\title{
A method to improve repeatability and reproducibility of the results of examination of the rate of heat released by shipbuilding materials
}

\author{
Krzysztof Sychta, Ph. D., \\ Sychta Laboratory General Partnership, Poland
}

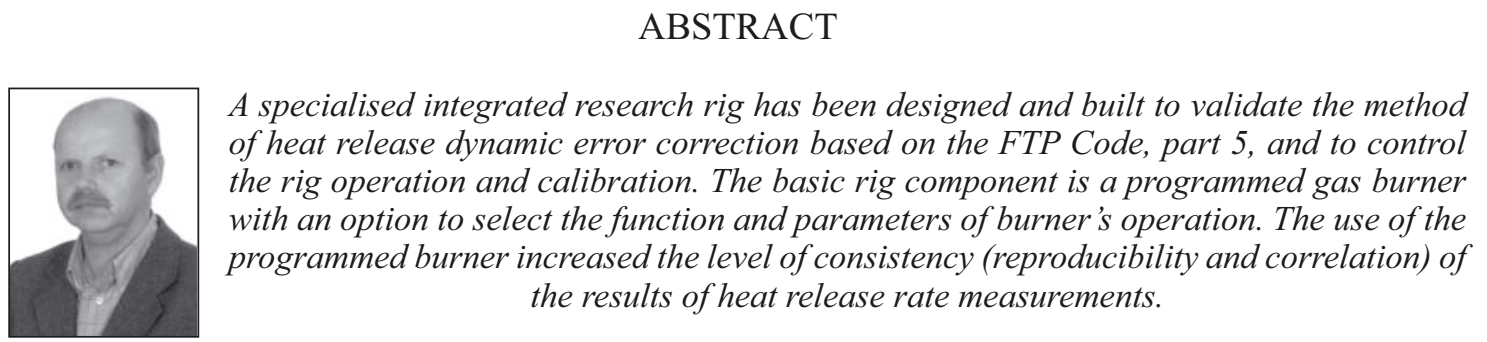

Key words: intensity of the secretion of the warmth; dynamic measurements; dynamic error

\section{INTRODUCTION}

The energy potential collected in materials can, but does not have to, be released during the fire. The final effect will depend on:

- resistance of materials to the action of external ignition sources,

- combustion efficiency of particular materials, defined by the mass which was subject to gasification,

- rate of heat release during thermal decomposition and combustion of the material,

a result of which successive portions of the burning material, or adjacent materials, can, but do not have to, be subject to ignition.

The heat release rate is also decisive for the rate of fire temperature changes, and the emission of smoke and toxic decomposition products during thermal decomposition and combustion of materials. Therefore from the point of view of prevention of fire spreading in an arbitrary technical object the object of interest, among other factors, is:

- resistance of the material or product to the action of external ignition sources,

- analysis of possible ignition caused by this material or product to the next successive elements of its surface and adjacent materials.

Propagation of flames over the material surface can be described by parameters determining this propagation, which are:

- critical heat flux,

- heat needed to maintain flaming combustion,

- heat release rate,

- heat emitted during thermal decomposition and combustion,

- possibility to create droplet fall.
The above quantities characterise thermal conditions which are necessary to start and maintain flaming combustion. The two first parameters are responsible for the resistance of the material (product) to the action of external ignition sources, while the remaining three - for material's potential to ignite fire in adjacent materials.

The critical heat flux and the heat needed to maintain flaming combustion are the measures of minimal thermal power of the ignition source which is necessary to start the self-maintaining process of material combustion.

Important material parameters which are decisive for fire danger in technical objects are the heat release rate and thermal potential of the material used. In the shipbuilding industry the heat release rate is determined during the examination of the surface flammability level of materials, done using the method described in FTP Code, part 5, IMO [1]. The surface of the sample of the examined material is placed vertically (Fig. 1) and heated by the heat flux of standardised distribution generated by the gas-fired radiant heating panel.

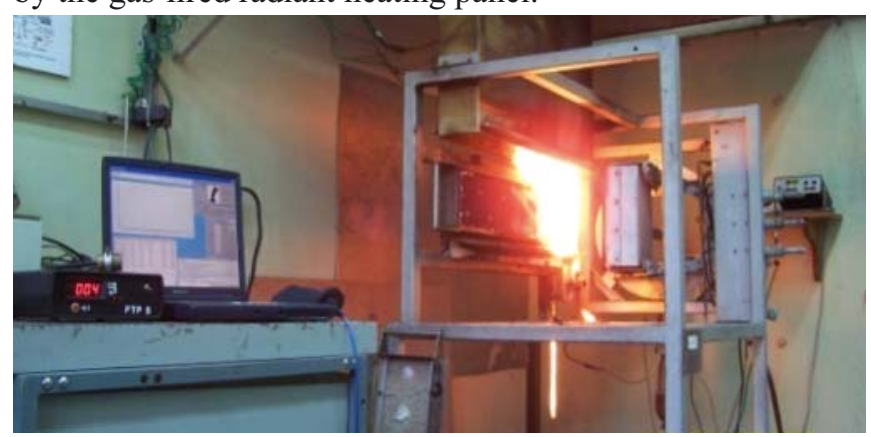

Fig. 1. Research rig examining surface flammability level of materials according to FTP Code, part 5

The flame spreads along the sample in the decreasing heat flux direction before it autonomously extincts. The material 
sample is examined at the presence of the flame of a pilot burner. The heat release rate $-\dot{\mathrm{q}}(\mathrm{t})$ and the amount of heat $\mathrm{Q}_{t}$ released by the sample are calculated from the formulas:

$$
\begin{gathered}
\mathrm{q}_{\mathrm{p}}=\beta(\mathrm{T}) \cdot\left(\mathrm{T}_{\mathrm{m}}-\mathrm{T}_{\mathrm{o}}\right) \\
\mathrm{Q}_{\mathrm{t}}=\int_{0}^{\mathrm{t}_{\mathrm{k}}} \beta(\mathrm{T}) \cdot\left(\mathrm{T}(\mathrm{t})-\mathrm{T}_{\mathrm{o}}\right) \cdot d \mathrm{t}
\end{gathered}
$$

where:

$\beta(T)$ - thermal equivalent of the research rig chimney duct, determined experimentally during rig calibration, $[\mathrm{kW} / \mathrm{K}]$,

$\mathrm{T}(\mathrm{t})$ - maximal temperature of gases in the chimney duct, [K],

$\mathrm{T}_{\mathrm{o}}$ - initial temperature of gases in the chimney duct, $[\mathrm{K}]$,

$\mathrm{t}$ - time, $[\mathrm{s}]$.

\section{FACTORS AFFECTING THE RESULT OF THE MEASUREMENT OF THE INTENSITY OF THE HEAT}

The rate of heat release during thermal decomposition and combustion of the examined materials is measured using the method described in the FTP Code, part 5, in the open system (Fig. 1) without any forced gas flow through the chimney.

For the assumed initial conditions (without the burning sample or reference gas) the total thermal balance has the form:

$$
\begin{gathered}
\dot{\mathrm{Q}}_{\mathrm{gpr}}+\dot{\mathrm{Q}}_{\mathrm{gp}}=\dot{\mathrm{Q}}_{\mathrm{gk}}^{\mathrm{o}}+\dot{\mathrm{Q}}_{\mathrm{strat}}^{\mathrm{o}} \\
\dot{\mathrm{Q}}_{\mathrm{gk}}^{\mathrm{o}}=\dot{\mathrm{V}}_{\mathrm{gk}}^{\mathrm{o}} \cdot \mathrm{c}_{\mathrm{p}} \cdot\left(\mathrm{T}_{\mathrm{o}}-\mathrm{T}_{\mathrm{ot}}\right)=\dot{\mathrm{V}}_{\mathrm{gk}}^{\mathrm{o}} \cdot \mathrm{c}_{\mathrm{p}} \cdot \Delta \mathrm{T}_{\mathrm{o}} \\
\dot{\mathrm{Q}}_{\mathrm{strat}}^{\mathrm{o}}=\sum_{\mathrm{i}=1}^{4} \sum_{\mathrm{j}=1}^{3} \dot{\mathrm{Q}}_{\mathrm{ijo}}^{\mathrm{o}}
\end{gathered}
$$

where:

$\dot{\mathrm{Q}}_{\mathrm{gk}}^{\circ}$ - heat flux carried out with the gases flowing through the chimney duct at given initial conditions, [kW],

$\dot{\mathrm{Q}}_{\mathrm{gpr}}$ - thermal power of the radiant heating panel, [kW],

$\mathrm{Q}_{\mathrm{gp}}$ - thermal power of the gas pilot burner, [kW],

$\dot{\mathrm{Q}}_{\text {strat }}^{\mathrm{O}}$ - total heat flux carried out to the environment at initial conditions, [kW],

$\dot{\mathrm{Q}}_{\mathrm{ijo}}$ - heat flux of $\mathrm{j}$-th type (1 - radiation, 2 - convection, 3 - conduction) flowing from the source and to the environment, [kW],

$\dot{\mathrm{V}}_{\mathrm{gk}}^{\mathrm{o}}$ - volumetric flow rate of gases in the chimney duct at initial conditions, $\left[\mathrm{m}^{3} \cdot \mathrm{s}^{-1}\right]$,

$\mathrm{c}_{\mathrm{p}} \quad-$ specific heat of gases, $\left[\mathrm{kJ} \cdot \mathrm{m}^{-3} \cdot \mathrm{K}^{-1}\right]$,

$\mathrm{T}_{\mathrm{o}} \quad$ - initial temperature of gases in the chimney duct, $[\mathrm{K}]$,

$\mathrm{T}_{\text {ot }} \quad$ - ambient temperature, $[\mathrm{K}]$.

The total thermal balance for the rig with the burning sample or reference gas has the form:

$$
\begin{gathered}
\dot{\mathrm{Q}}_{\mathrm{gpr}}+\dot{\mathrm{Q}}_{\mathrm{gp}}+\dot{\mathrm{Q}}_{\mathrm{p}}=\dot{\mathrm{Q}}_{\mathrm{gk}}+\dot{\mathrm{Q}}_{\mathrm{strat}} \\
\dot{\mathrm{Q}}_{\mathrm{gk}}=\dot{\mathrm{V}}_{\mathrm{gk}} \cdot \mathrm{c}_{\mathrm{p}} \cdot\left(\mathrm{T}_{\mathrm{g}}-\mathrm{T}_{\mathrm{ot}}\right)=\dot{\mathrm{V}}_{\mathrm{gk}} \cdot \mathrm{c}_{\mathrm{p}} \cdot \Delta \mathrm{T}_{\mathrm{g}} \\
\dot{\mathrm{Q}}_{\text {strat }}=\sum_{\mathrm{i}=1}^{4} \sum_{\mathrm{j}=1}^{3} \dot{\mathrm{Q}}_{\mathrm{ijo}}
\end{gathered}
$$

where:

$\dot{\mathrm{Q}}_{\mathrm{p}} \quad$ - rate of heat release during thermal decomposition and combustion of the sample of the examined material or reference gas, $[\mathrm{kW}$,

$\dot{\mathrm{Q}}_{\mathrm{gk}}$ - heat flux carried out with gases flowing through the chimney duct, [kW],
$\dot{\mathrm{Q}}_{\text {strat }}$ - total heat flux carried out to the environment, $[\mathrm{kW}]$,

$\dot{Q}_{i j o}$ - heat flux of $\mathrm{j}$-th type (1 - radiation, 2 - convection, 3 - conduction) flowing from the source and to the environment, $[\mathrm{kW}]$,

$\dot{\mathrm{V}}_{\mathrm{gk}}$ - volumetric flow rate of gases in the chimney duct, $\left[\mathrm{m}^{3} \cdot \mathrm{s}^{-1}\right]$,

$\mathrm{c}_{\mathrm{p}} \quad$ - specific heat of gases, $\left[\mathrm{kJ} \cdot \mathrm{m}^{-3} \cdot \mathrm{K}^{-1}\right]$,

$\mathrm{T}_{\mathrm{g}} \quad$ - temperature of gases in the chimney duct, $[\mathrm{K}]$,

$\mathrm{T}_{\mathrm{ot}}$ - ambient temperature, [K].

After transformation of the research rig thermal balance equation system we get the formula for the heat release rate during thermal decomposition and combustion of the sample of the examined material or reference gas [2]:

$$
\begin{gathered}
\dot{\mathrm{Q}}_{\mathrm{p}}=\left(\dot{\mathrm{Q}}_{\mathrm{gk}}-\dot{\mathrm{Q}}_{\mathrm{gk}}^{\mathrm{o}}\right)+\left(\dot{\mathrm{Q}}_{\mathrm{strat}}-\dot{\mathrm{Q}}_{\text {strat }}^{\mathrm{o}}\right)= \\
=\dot{\mathrm{V}}_{\mathrm{gk}} \cdot \mathrm{c}_{\mathrm{p}} \cdot \Delta \mathrm{T}_{\mathrm{g}}-\dot{\mathrm{V}}_{\mathrm{gk}}^{\mathrm{o}} \cdot \mathrm{c}_{\mathrm{p}} \cdot \Delta \mathrm{T}_{\mathrm{o}}+\left(\dot{\mathrm{Q}}_{\mathrm{strat}}-\dot{\mathrm{Q}}_{\text {strat }}^{\mathrm{o}}\right) \\
\dot{\mathrm{Q}}_{\mathrm{p}}=\beta_{1} \cdot\left(\Delta \mathrm{T}_{\mathrm{g}}-\Delta \mathrm{T}_{\mathrm{o}}\right)+\beta_{2} \cdot\left(\Delta \mathrm{T}_{\mathrm{g}}-\Delta \mathrm{T}_{\mathrm{o}}\right)= \\
=\left(\beta_{1}+\beta_{2}\right) \cdot\left(\Delta \mathrm{T}_{\mathrm{g}}-\Delta \mathrm{T}_{\mathrm{o}}\right) \\
\dot{\mathrm{Q}}_{\mathrm{p}}=\beta\left(\Delta \mathrm{T}_{\mathrm{g}}\right) \cdot\left(\Delta \mathrm{T}_{\mathrm{g}}-\Delta \mathrm{T}_{\mathrm{o}}\right)
\end{gathered}
$$

where:

$\beta_{1} \cdot\left(\Delta \mathrm{T}_{\mathrm{g}}-\Delta \mathrm{T}_{\mathrm{o}}\right)=\dot{\mathrm{V}}_{\mathrm{gk}} \cdot \mathrm{c}_{\mathrm{p}} \cdot \Delta \mathrm{T}_{\mathrm{g}}-\dot{\mathrm{V}}_{\mathrm{gk}}^{\mathrm{o}} \cdot \mathrm{c}_{\mathrm{p}} \cdot \Delta \mathrm{T}_{\mathrm{o}}$

$\beta_{2} \cdot\left(\Delta \mathrm{T}_{\mathrm{g}}-\Delta \mathrm{T}_{\mathrm{o}}\right)=\dot{\mathrm{Q}}_{\text {strat }}-\dot{\mathrm{Q}}_{\text {strat }}^{\mathrm{o}}$

$\beta\left(\Delta \mathrm{T}_{\mathrm{g}}\right)=\beta_{1}+\beta_{2}$

It results from the above analysis that the rig is a converter measuring the heat release rate during thermal decomposition and combustion of samples of examined materials. High repeatability of the measured results can be obtained when repeatable conditions are preserved for:

- heat transfer between rig components and the environment, - thermal decomposition and combustion of the examined material.

That means absolute necessity to preserve conditions, defined by a relevant standard for the given method, for thermal decomposition and combustion of samples of the examined materials. This requirement also refers to the environment and geometrical structure of the rig, which affect considerably the heat transfer between its individual components and that taking place in the zone of thermal decomposition and combustion of samples of examined materials.

The converter used for measuring heat release rate during thermal decomposition and combustion of samples of the examined materials with the aid of the calorimetric method given in the FTP Code, part 5, is the entire research rig which converts the measured quantity (heat release rate) to voltage. The heat release rate measured on the rig is a function of voltage signal at measuring system output:

$$
\dot{\mathrm{Q}}_{\mathrm{p}}(\mathrm{t})=\beta(\mathrm{U}) \cdot\left[\mathrm{U}(\mathrm{t})-\mathrm{U}_{\mathrm{o}}\right]
$$

where:

$\beta(\mathrm{U})$ - thermal equivalent of the rig, calculated experimentally during its calibration, $\left[\mathrm{kW} \cdot \mathrm{mV}^{-1}\right]$,

$\mathrm{U}$ - voltage at output of the difference system measuring the temperature of gases in the chimney duct, $[\mathrm{mV}]$,

$\mathrm{U}_{\mathrm{o}} \quad$ - initial voltage at output of the difference system measuring the temperature of gases in the chimney duct, $[\mathrm{mV}]$.

The thermal equivalent of the rig is the thermal power which is to be continuously delivered to the chimney duct to keep 
the elementary signal increment of the system measuring the temperature of the gases flowing through it steady:

$$
\beta=\frac{\dot{q}}{U_{m}-U_{o}}
$$

where:

$\beta$ - thermal equivalent of the rig, $\left[\mathrm{kW} \cdot \mathrm{mV}^{-1}\right]$,

$\dot{\mathrm{q}}$ - thermal power, $[\mathrm{kW}]$,

$U_{m}$ - maximal signal of the temperature measurement system, [mV],

$U_{o}$ - initial signal of temperature measurement system, [mV].

The thermal equivalent of the rig is determined experimentally during rig calibration by combusting a gas with known combustion heat in conditions identical to those in which material samples are examined. The process of calibration of the heat release rate system is to be compatible with the real process of the heat release rate measurement during material examination. When this condition was not met in the past, it led to different results of examination of the same materials done in different laboratories.

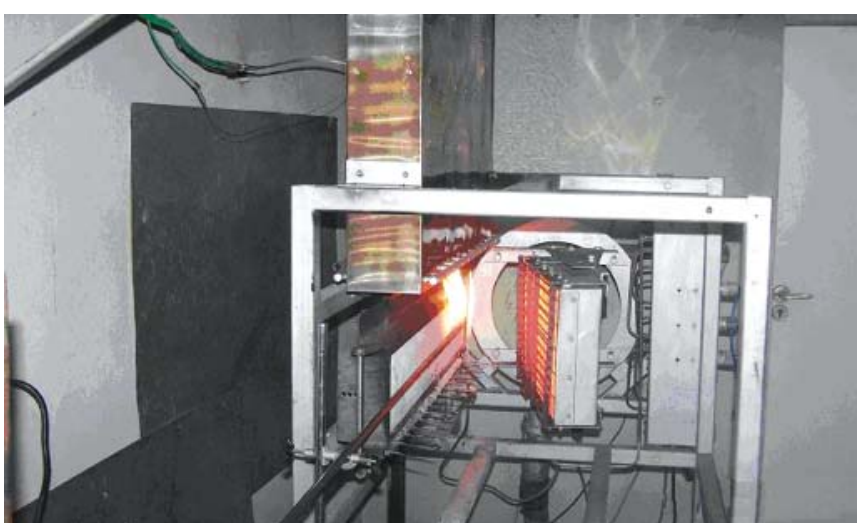

Fig. 2. Rig measuring surface combustibility level of materials, according to FTP Code, part 5, with a calibration burner for thermal equivalent calculation
A scheme of the measuring system to determine the thermal equivalent of the rig is given in Fig. 3.

Manometer

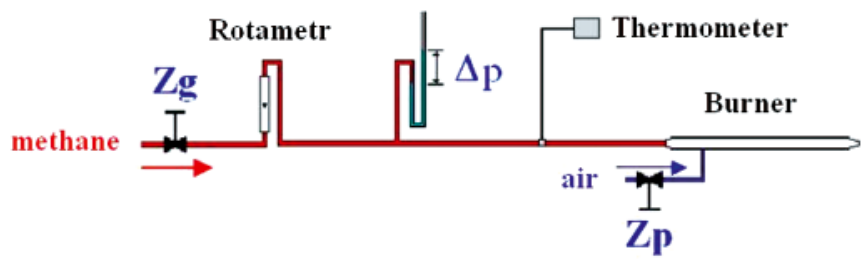

Fig. 3. Scheme of feeding of the linear burner used for rig calibration

The amount of the released heat and the rate of its release measured by the system are to be compared with the power of the burner and the amount of the heat delivered to the rig:

$$
\begin{gathered}
\dot{\mathrm{q}}=\frac{\mathrm{T}_{\mathrm{o}}}{\mathrm{T}_{\mathrm{g}}} \cdot \frac{\mathrm{p}_{\mathrm{b}}+\Delta \mathrm{p}}{\mathrm{p}_{\mathrm{o}}} \cdot \dot{\mathrm{V}} \cdot \mathrm{c}_{\mathrm{sp}} \\
\mathrm{Q}_{\mathrm{c}}=\frac{\mathrm{T}_{\mathrm{o}}}{\mathrm{T}_{\mathrm{g}}} \cdot \frac{\mathrm{p}_{\mathrm{b}}+\Delta \mathrm{p}}{\mathrm{p}_{\mathrm{o}}} \cdot \mathrm{V} \cdot \mathrm{c}_{\mathrm{sp}}
\end{gathered}
$$

where:

$\mathrm{T}_{\mathrm{o}} \quad$ - gas temperature at normal conditions, $[\mathrm{K}]$,

$\mathrm{T}_{\mathrm{g}} \quad$ - temperature of the combusted gas, $[\mathrm{K}]$,

$\mathrm{p}_{\mathrm{b}} \quad$ - barometric pressure, $[\mathrm{Pa}]$,

$\Delta \mathrm{p} \quad$ - overpressure of the combusted gas, $[\mathrm{Pa}]$,

$\underline{p_{0}} \quad-$ gas pressure at normal conditions, $[\mathrm{Pa}]$,

$\overline{\mathrm{V}} \quad$ - average volumetric gas flow rate, $\left[\mathrm{m}^{3} \cdot \mathrm{s}^{-1}\right]$,

$\mathrm{V}$ - volume of the combusted gas, $\left[\mathrm{m}^{3}\right]$,

$\mathrm{c}_{\mathrm{sp}} \quad$ - combustion heat of the gas, $\left[\mathrm{kJ} \cdot \mathrm{m}^{-3}\right]$.

The thermal equivalent of the rig is calculated from the formula:

$$
\beta=\frac{\mathrm{T}_{\mathrm{o}}}{\mathrm{T}_{\mathrm{g}}} \cdot \frac{\mathrm{p}_{\mathrm{b}}+\Delta \mathrm{p}}{\mathrm{p}_{\mathrm{o}}} \cdot \frac{\overline{\dot{\mathrm{V}}} \cdot \mathrm{c}_{\mathrm{sp}}}{\mathrm{U}_{\mathrm{m}}-\mathrm{U}_{\mathrm{o}}}
$$

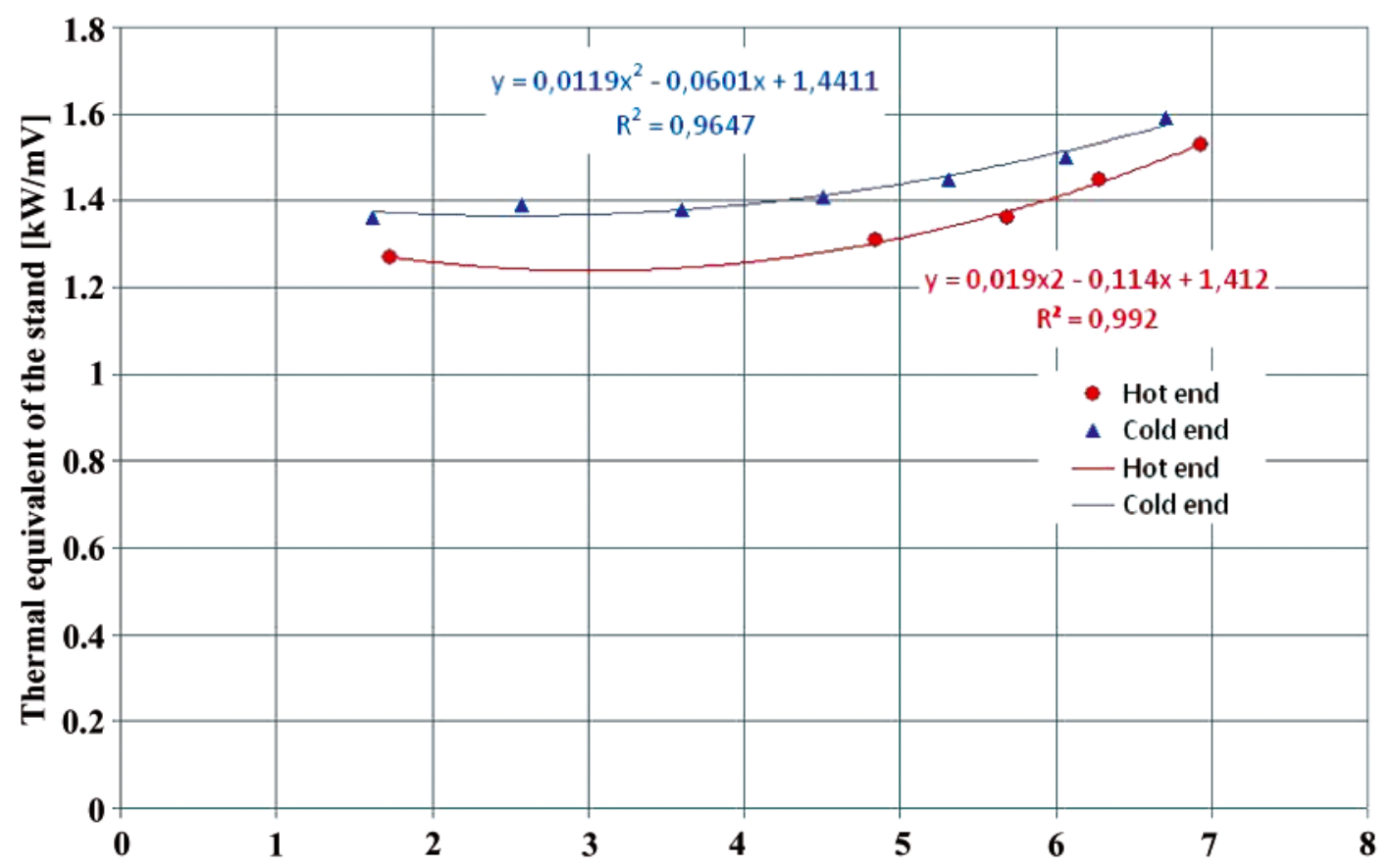

Value of the signal on the outing of the converter to the measurement of heat release rate [mV]

Fig. 4. Results of measurements of thermal equivalent $\beta$ of the KTZO rig used for examining surface combustibility of shipbuilding materials with the aid of the method of Resolution A.653(16) 
where:

$\mathrm{T}_{\mathrm{o}} \quad$ - gas temperature at normal conditions, $[\mathrm{K}]$,

$\mathrm{T}_{\mathrm{g}} \quad$ - temperature of the combusted gas, $[\mathrm{K}]$,

$\mathrm{p}_{\mathrm{b}} \quad$ - barometric pressure, $[\mathrm{Pa}]$,

$\Delta \mathrm{p} \quad$ - overpressure of the combusted gas, $[\mathrm{Pa}]$,

$\mathrm{p}_{\mathrm{o}} \quad$ - gas pressure at normal conditions, $[\mathrm{Pa}]$,

$\overline{\mathrm{V}} \quad$ - average volumetric gas flow rate, $\left[\mathrm{m}^{3} \cdot \mathrm{s}^{-1}\right]$,

$\mathrm{c}_{\mathrm{sp}} \quad$ - combustion heat of the gas, $\left[\mathrm{kJ} \cdot \mathrm{m}^{-3}\right]$,

$U_{m} \quad$ - maximal signal of the temperature measurement system, $[\mathrm{mV}]$,

$U_{o} \quad$ - initial signal of the temperature measurement system, $[\mathrm{mV}]$.

Due to heat losses, the thermal equivalent of the rig is not constant and depends on the combustion gas temperature, $\beta(U)=f(U)$, while the relevant standard assumes its constant value.

The combined uncertainty of the heat release rate measurement rig is given by the equation system [2]:

$$
\frac{\mathrm{u}_{\mathrm{c}}\left(\dot{\mathrm{Q}}_{\mathrm{p}}\right)}{\dot{\mathrm{Q}}_{\mathrm{p}}}=\sqrt{\left[\frac{\mathrm{u}(\beta)}{\beta}\right]^{2}+\left[\frac{\mathrm{u}(\mathrm{U})}{\mathrm{U}}\right]^{2}+\left[\frac{\mathrm{u}\left(\mathrm{U}_{\mathrm{o}}\right)}{\mathrm{U}_{\mathrm{o}}}\right]^{2}}
$$

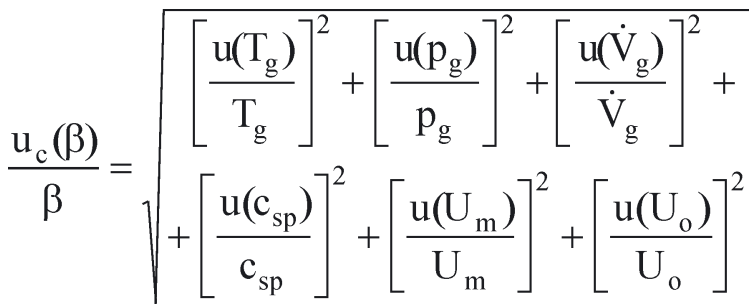

where:

$u(\beta)$ - standard uncertainty of measurement of thermal equivalent of the rig, $\left[\mathrm{kW} \cdot \mathrm{mV}^{-1}\right]$,

$\mathrm{u}(\mathrm{U})$ - standard uncertainty of voltage measurement at outlet of the difference system which measures gas temperature in the chimney duct, $[\mathrm{mV}]$,
$\mathrm{u}\left(\mathrm{U}_{\mathrm{o}}\right)$ - standard uncertainty of initial voltage measurement at outlet of the difference system which measures gas temperature in the chimney duct, $[\mathrm{mV}]$.

$\mathrm{u}\left(\mathrm{T}_{\mathrm{g}}\right)$ - standard uncertainty of temperature measurement of the gas delivered to the burner, $[\mathrm{K}]$,

$\mathrm{u}\left(\mathrm{p}_{\mathrm{b}}\right)$ - standard uncertainty of pressure measurement of the combusted gas, $[\mathrm{Pa}]$,

$\mathrm{u}(\overline{\mathrm{V}})$ - standard uncertainty of volumetric gas flow rate measurement, $\left[\mathrm{m}^{3} \cdot \mathrm{s}^{-1}\right]$,

$\mathrm{u}\left(\mathrm{c}_{\mathrm{sp}}\right)$ - standard uncertainty of combustion heat measurement for methane, $\left[\mathrm{kJ} \cdot \mathrm{m}^{-3}\right]$,

$\mathrm{u}\left(\mathrm{U}_{\mathrm{m}}\right)$ - standard uncertainty of measurement of maximal voltage at outlet of the difference system which measures gas temperature in the chimney duct, [mV],

$\mathrm{u}\left(\mathrm{U}_{\mathrm{o}}\right)$ - standard uncertainty of initial voltage measurement at outlet of the difference system which measures gas temperature in the chimney duct, $[\mathrm{mV}]$.

Rig parameters and voltage $U$ at difference system outlet, being the basis for estimating the gas temperature in the chimney duct, were measured using an integrated control and measurement system with a 20-bit A/D converter (Fig. 5). Standard uncertainty for the average value $U$ measured by the voltage system is $0.001 \mathrm{mV}$. That means that the basic component of uncertainty when measuring heat release rate using the method of the FTP Code, part5, is uncertainty of the measurement of thermal equivalent $\beta(\mathrm{U})$ of the rig.

The extended combined uncertainty of the rig for heat release rate measurements making use of the FTP Code, part 5, method is obtained from the formula:

$$
\mathrm{U}=\mathrm{k} \cdot \mathrm{u}_{\mathrm{c}}(\mathrm{y})
$$

Since standard partial uncertainties were estimated from small numbers of measurements, the t-Student distribution was used for determining the extension coefficient. For the confidence level equal to 0.95 the assumed extension coefficient was 3.18. The extended uncertainty of the rig owned by the Faculty of Technical Ship Service is $0.2 \mathrm{~kW}$.

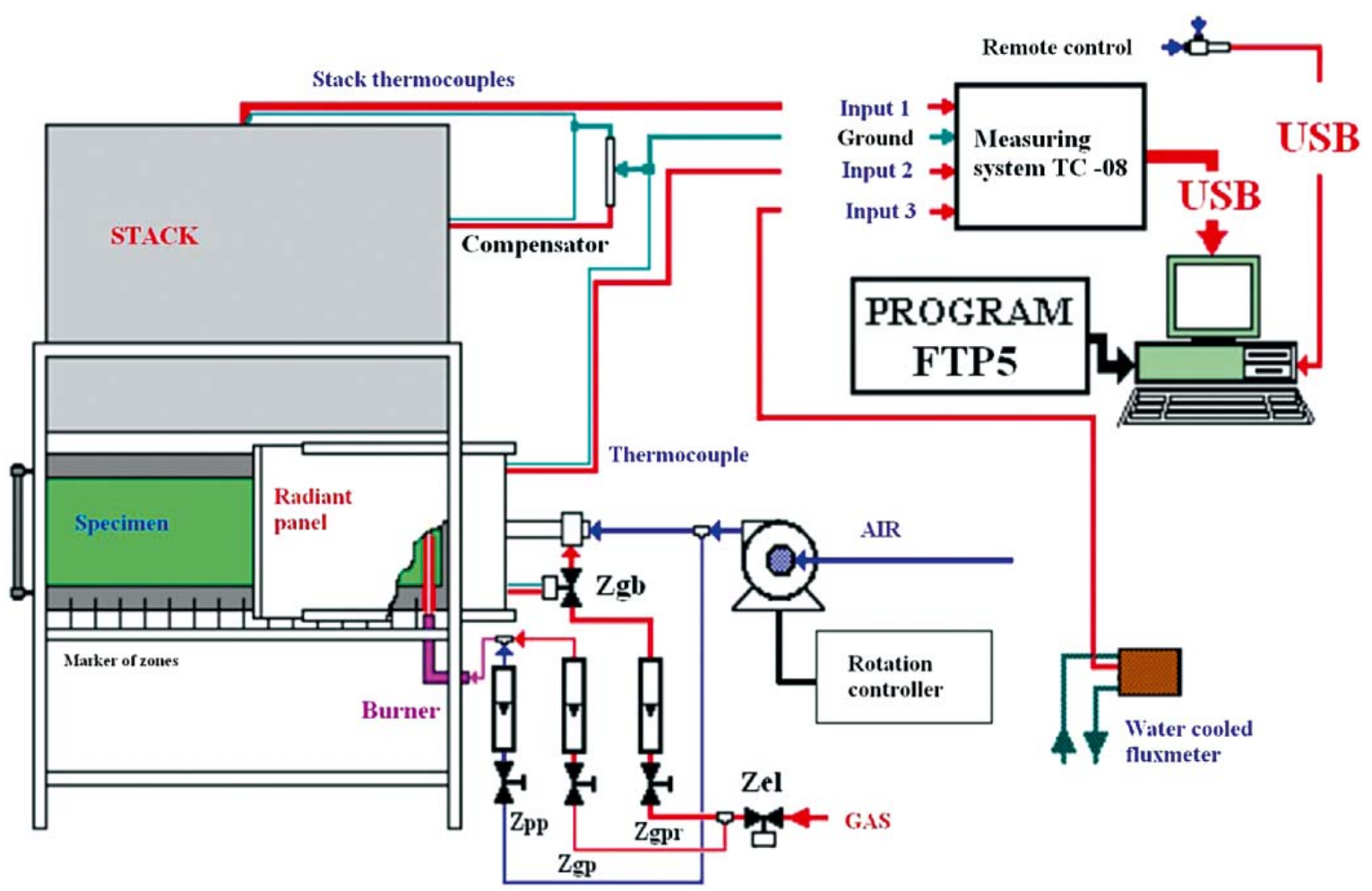

Fig. 5. Scheme of research rig examining the level of surface combustibility of materials, according to FTP Code, part 5 


\section{DYNAMIC ERROR CORRECTION METHOD}

Since the material combustion is a dynamic process, the heat release rate measurement should also be considered a dynamic measurement. The identification of the research rig as the converter for heat release rate measurement consisted in defining the structure and functional relations which describe dynamic characteristics of the measuring system. This made it possible to conclude that $[2,3]$ the research rig measuring the heat release rate with the aid of the method of the FTP Code, part 5, (Res. A.653(16)) is the second order converter characterised by: time constant $\mathrm{T}_{1}$, time constant $\mathrm{T}_{2}$, attenuation coefficient $\zeta$, and free-vibration pulsation coefficient $\omega_{0}$.

Correction of the dynamic error of the rig working in accordance with the FTP Code, part 5, was done using the response of the rig to a linearly increasing excitation. The response of the second order converter to the linearly increasing excitation $\mathrm{x}(\mathrm{t})=\mathrm{a} \cdot \mathrm{t}$ has the form [2]:

$\left.y(t)=a \cdot t-\frac{2 \cdot \zeta}{\omega_{0}}+\frac{\frac{1}{T_{2}^{2}} \cdot \exp \left(-\frac{t}{T_{1}}\right)-\frac{1}{T_{1}^{2}} \cdot \exp \left(-\frac{t}{T_{2}}\right)}{\omega_{0}^{2} \cdot\left(\frac{1}{T_{2}}-\frac{1}{T_{1}}\right)}\right]$

For sufficiently large values of $t$ the equation becomes:

$$
\lim _{t \rightarrow \infty} y(t)=a \cdot\left(t-\frac{2 \cdot \zeta}{\omega_{0}}\right)
$$

Consequently it can be assumed that in the time interval: $\mathrm{t}_{\mathrm{i}}-\Delta \mathrm{t}<\mathrm{t}_{\mathrm{i}}<\mathrm{t}_{\mathrm{i}}+\Delta \mathrm{t}$ (where $\Delta \mathrm{t}$ it the time of measurement) the measured heat release rate is a linear function with the change rate $\mathrm{a}_{\mathrm{i}}$ constant in this interval. The corrected value of the heat release rate is calculated from the formula:

$$
\begin{gathered}
\dot{\mathrm{q}}_{\mathrm{k}}\left(\mathrm{t}_{\mathrm{i}}\right)=\dot{\mathrm{q}}\left(\mathrm{t}_{\mathrm{i}}\right)+\mathrm{a}_{\mathrm{i}} \cdot \frac{2 \cdot \zeta}{\omega_{\mathrm{o}}}= \\
=\dot{\mathrm{q}}\left(\mathrm{t}_{\mathrm{i}}\right)+\frac{\dot{\mathrm{q}}\left(\mathrm{t}_{\mathrm{i}+1}\right)-\dot{\mathrm{q}}\left(\mathrm{t}_{\mathrm{i}-1}\right)}{\mathrm{t}_{\mathrm{i}+1}-\mathrm{t}_{\mathrm{i}-1}} \cdot \frac{2 \cdot \zeta}{\omega_{\mathrm{o}}}
\end{gathered}
$$

\section{VALIDATION OF A DYNAMIC ERROR CORRECTION METHOD}

The validation of the method correcting the dynamic error of the heat release rate measurement making use of the method

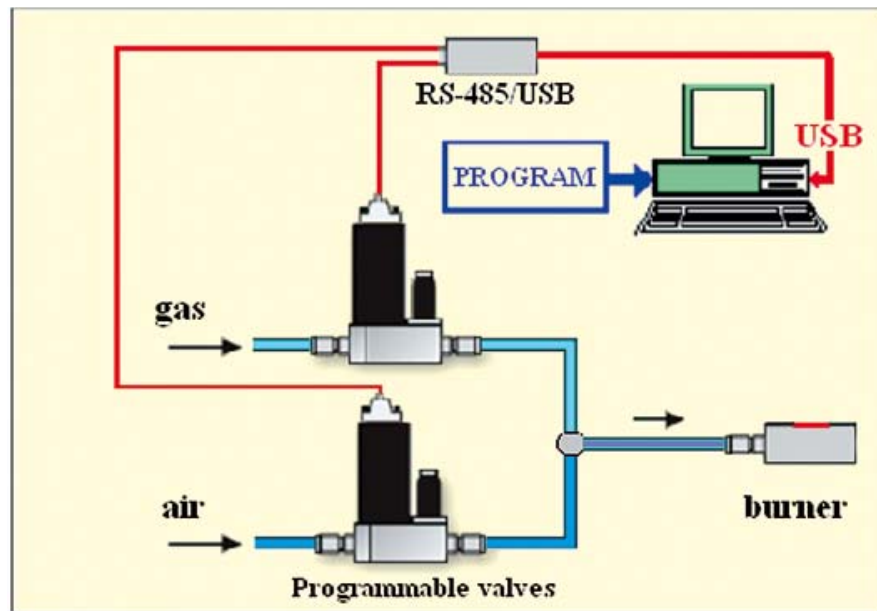

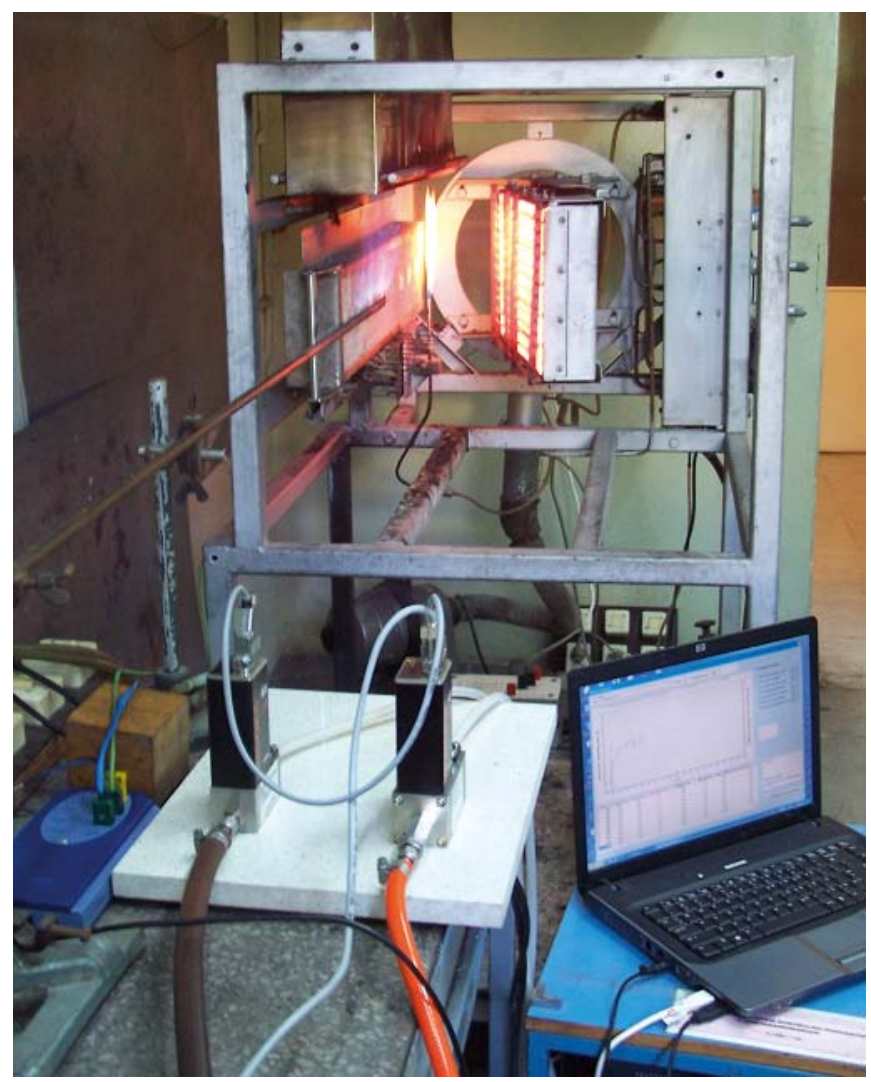

Fig. 7. Rig for examining heat release rate with the aid of the FTP Code, part 5, method

described in the FTP Code, part 5, was done using a specialised integrated research rig designed and built for this purpose. The basic component of the rig is a programmed gas burner with the option to select the function and parameters of burner's operation.

Taking into account dynamic characteristics of the rig has made it possible to improve the level of consistency (reproducibility and correlation) of the results of heat release rate measurements (Fig. 8, Fig. 9, Fig. 10), without introducing any changes to research rig structure and measuring procedures.

Taking into account dynamic characteristics of the rig has made it possible to improve the level of consistency (reproducibility and correlation) of the results of heat release rate measurements done using different methods, without introducing changes to research rig structures and measuring procedures (Fig. 11).

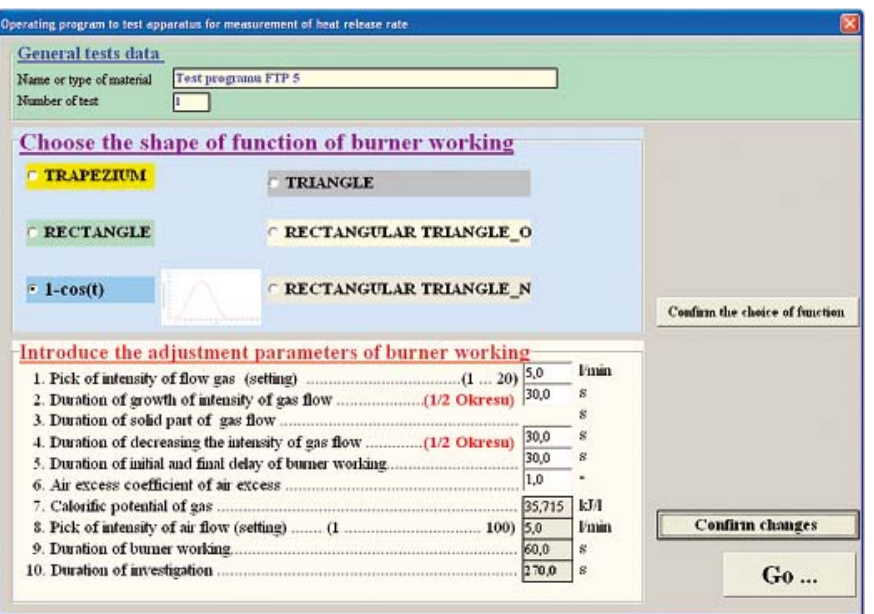

Fig. 6. Scheme of programmed gas burner 


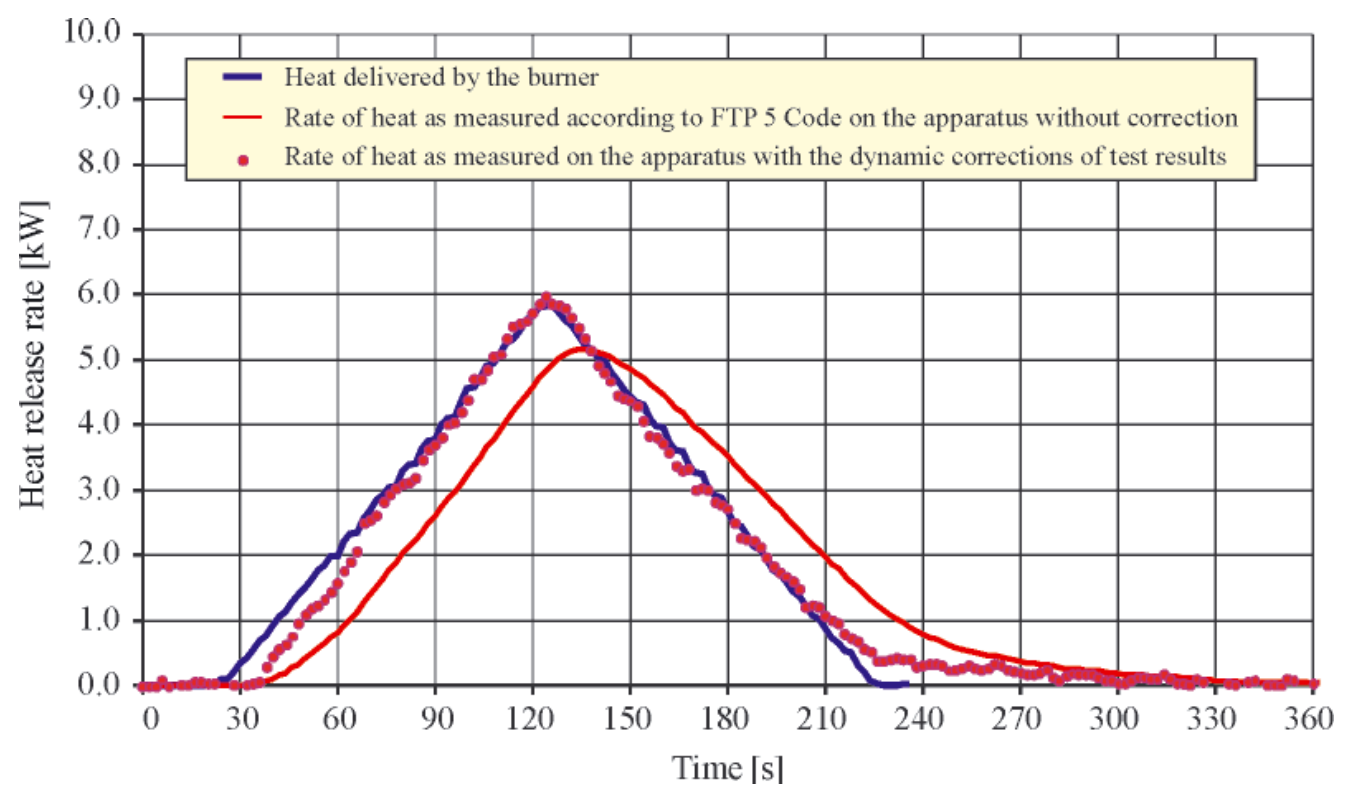

Fig. 8. Comparing results of the heat release rate of the programmed gas burner with that measured on the rig with the aid of the FTP Code, part 5, method - with and without dynamic error correction

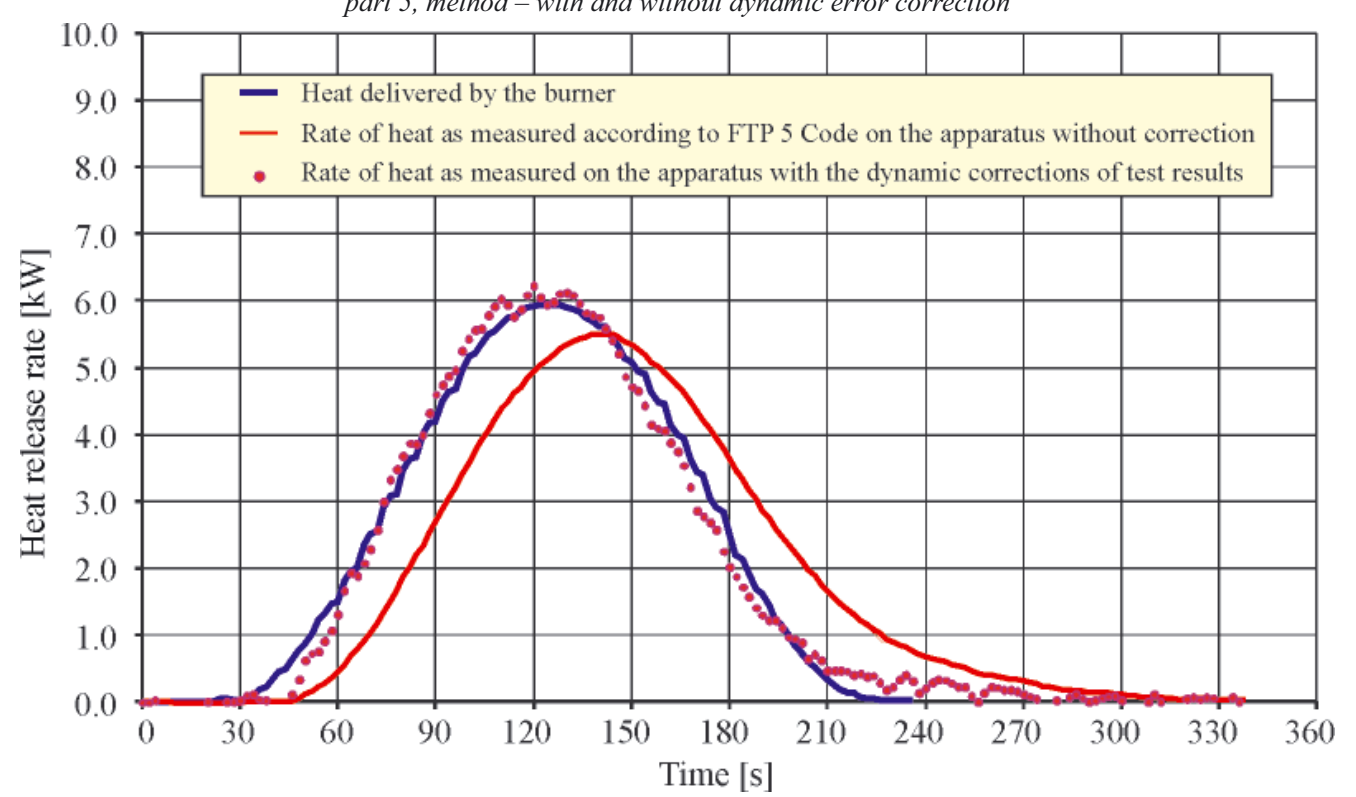

Fig. 9. Comparing results of the heat release rate of the programmed gas burner with that measured on the rig with the aid of the FTP Code, part 5, method - with and without dynamic error correction

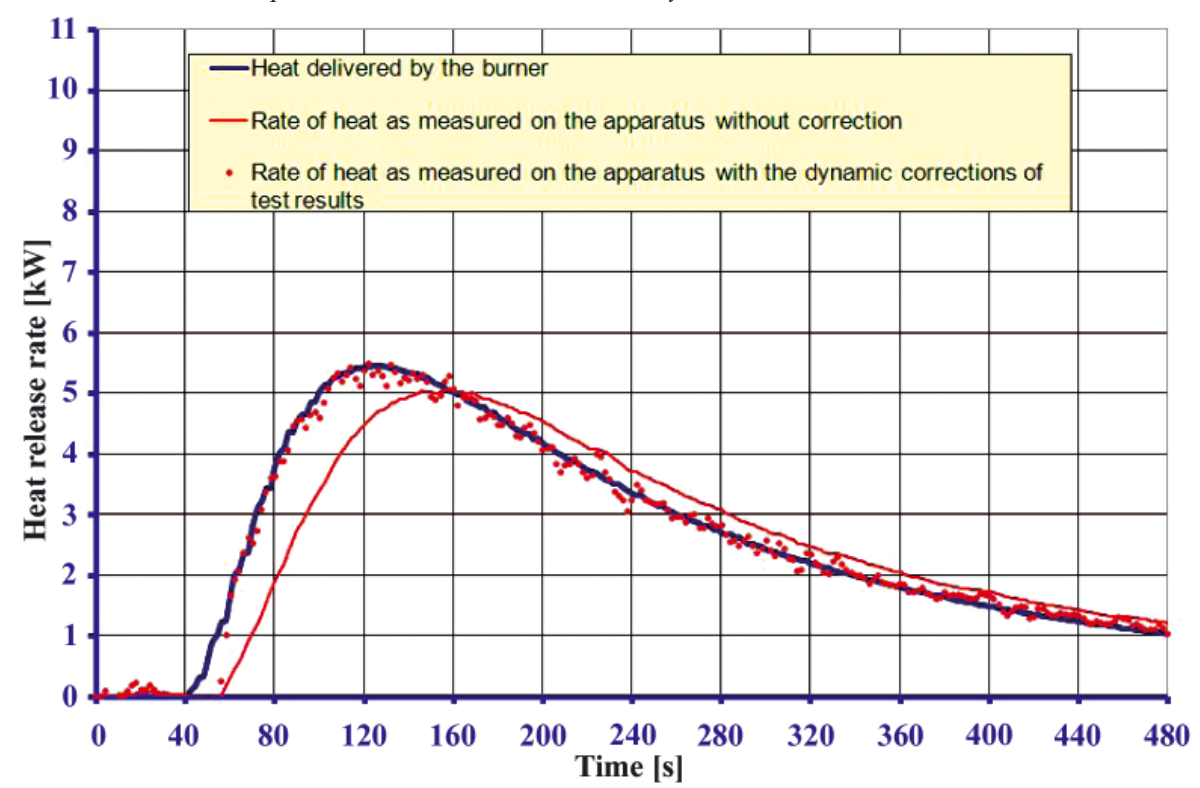

Fig. 10. Comparing results of the heat release rate of the programmed gas burner with that measured on the rig with the aid of the FTP Code, part 5, method - with and without dynamic error correction 


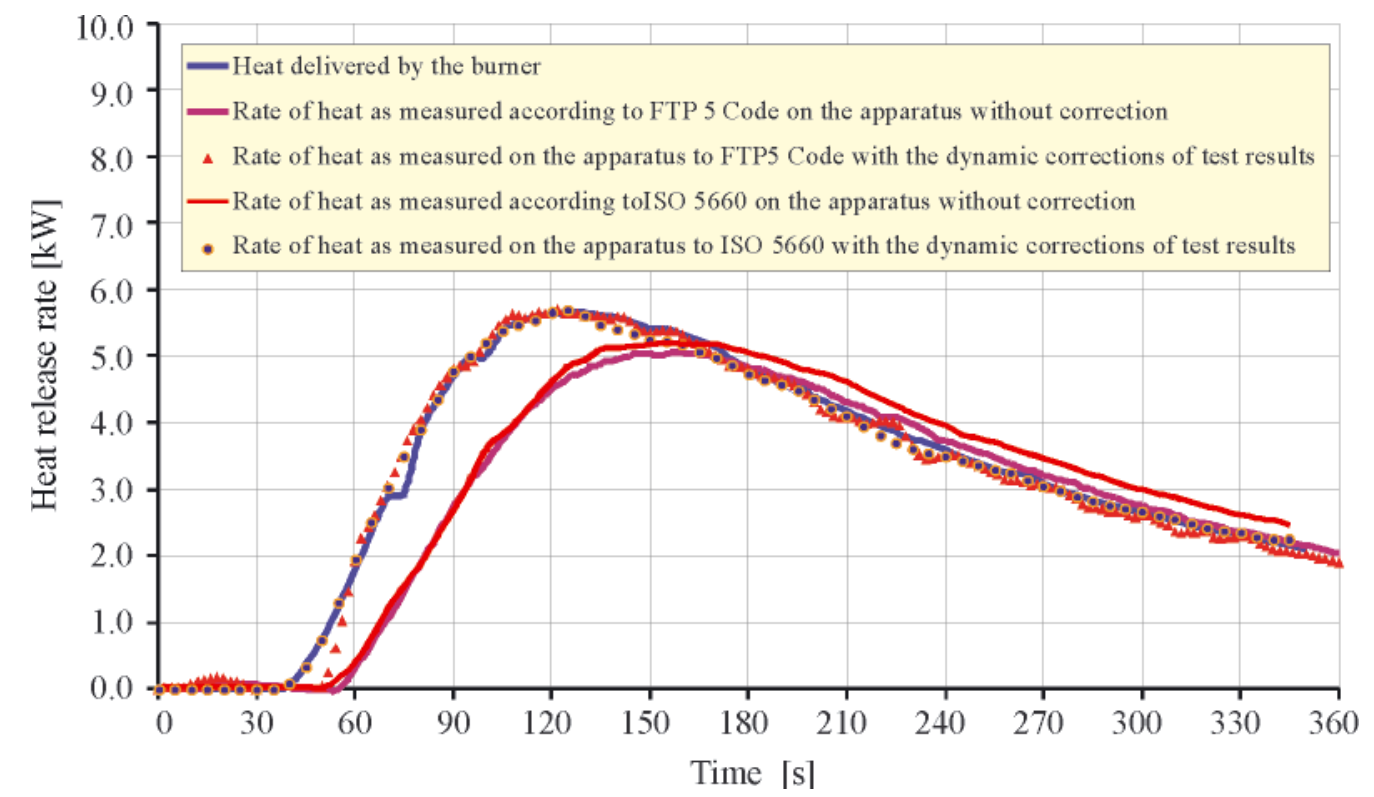

Fig. 11. Comparing results of the heat release rate of the programmed gas burner with the values measured on the rig using the FTP Code, part 5, method and on the ISO 5660 rig [4] - with and without dynamic error correction

\section{SUMMARY}

A basic factor which is decisive for poor correlation between results of heat release rate measurements done using different methods is treating the measurement in a conventional way as a static measurement. Since material combustion is a timedependent process, the heat release rate measurement should also be considered a dynamic process.

In order to validate and control the rig operation and the method used to correct the dynamic error of heat release rate measurement making use of the FTP Code, part 5, method, a specialised integrated research rig was designed and built. The basic component of this rig is a programmed gas burner with an option to select a function and parameters of burner's operation.

Taking into account dynamic parameters of the rig has made it possible to increase the level of consistency (reproducibility and correlation) of the results of heat release rate measurements obtained using different methods, without introducing any changes to research rigs and/or measuring procedures.

\section{BIBLIOGRAPHY}

1. International Code for Fire Test Procedures. Annex 1. Part 5. Surface Flammability Test. International Maritime Organization, London 1998

2. K. Sychta: Analiza porównawcza badań intensywności wydzielania ciepta przez materiaty okrętowe oraz metoda poprawy doktadności pomiaru. (Comparison and analysis of tests of the rate of heat release results of shipbuilding materials and the method of improvement of reproducibility of results). Doctors Thesis, Faculty of Maritime Technology, Szczecin Technical University, Szczecin 2006

3. K. Sychta: The analysis of research results concerning heat release rates of ship materials with regard to dynamic parameters of the research station. Polish Maritime Research, Vol. 15 (2008) pp. 56-59

4. ISO 5660-1: 2002, Reaction-to-fire tests . Heat release, smoke production and mass loss rate. Part 1: Heat release rate (cone calorimeter method)

\section{CONTACT WITH THE AUTHOR}

Krzysztof Sychta, Ph. D., Sychta Laboratory General Partnership,

Ofiar Stutthofu 50,

72-010 Police, POLAND

e-mail: biuro@sychta.eu phone: +48 913170161 